\title{
What context for liberated computer assisted language learning?
}

\author{
Pierre Frath \\ Pôle Universitaire Européen \\ Strasbourg \\ France
}

\begin{abstract}
Information Technology can certainly liberate the learners by providing them with a wealth of easily accessible learning resources, but success largely depends on the pedagogical context in which these are used. IT can be considered either as an extension of class-room work, or as a learning resource in a self-study environment, or as a blend of both. This paper focuses on multimedia computer assisted language learning in a guided self-study context. It describes the setting up and the running of a multimedia language centre at a department of a French university. It also assesses the experiment, discusses its results, and tries to define the general conditions in which effective computer assisted language learning may take place.
\end{abstract}

Main conference themes: flexible learning, learner centred learning

Educational areas: higher education

Study topics: languages

Secondary keywords: multimedia 


\section{INTRODUCTION}

Information technology (IT) as a tool for teaching or learning languages is all too often acquired by businesses, schools and universities without giving enough thought to the educational context in which it will be used by learners and teachers. Business executives buy CD-ROMs in the hope that staff members will learn languages on their own in their spare time; heads of language departments acquire multimedia authoring-systems without taking into account the amount of work involved and the inevitable re-organization of the teaching methods.

In what context can Computer Assisted Language Learning (CALL) be effective enough to justify the time and money spent on it? In this paper we describe and discuss use of IT as an integrated learning resource among other learning resources in a self-study context at the Biology and Geology Department of the UFR des Sciences de la Vie et de la Terre, Université Louis Pasteur, Strasbourg (France).

\section{TWO SCHOOLS OF THOUGHT: CLASS-ROOM STUDY AND SELF-STUDY}

IT is necessarily used in one of two classes of contexts: a class-room or a selfstudy context (or in a blend of both).

In the first case, IT is used as an extension of traditional teaching. Part of the learning is done with a teacher using traditional teaching materials and methods, but the teacher takes advantage of the availability of computers to have students restudy parts of the curriculum or to have them study more intensively. IT can thus be fairly easily integrated into the existing teaching methods, in much the same way as the tape-recorder, the language laboratory or the use of video-taped material have been successfully integrated into standard teaching practices over the past decades. In this case, IT is part of a working pedagogical context in a sort of self-evident way. Problems may still arise, for example by uninformed choice of IT resources, in which case investment of time and effort in the design of CALL lessons is not worthwhile [1].

IT may also be considered as a freely available learning resource. People in charge then often assume that the simple availability of computers and adequate software will, magically, prompt effective learning. Unfortunately, after a short period of interest, this sort of tool-centred learning can rapidly lead to disaster.

A way to avoid this outcome is to use IT in the more general context of what is known as guided self-study [2]. Guided self-study rests on the premise that most students are willing to work on their own, if they are provided with 
adequate learning resources and guidance, and if progress can be assessed. How learning is done is still widely discussed, but one thing is certain: no two students use exactly the same learning strategies [3]. A wide choice of resources and methods must therefore be offered to students to help them find strategies fitting their learning styles. If choice means liberty, self-study indeed liberates the learner.

Self-study often takes place in a Language Centre instead of a traditional classroom. The teacher's role in a Language Centre is to create self-study lessons (or to buy them on the market and make them available), to regulate the flow of students, to help them organize their curriculum according to needs and interests, to offer guidance and, if need be, tutoring. Thus, teaching does not necessarily take place at the same time as learning, and the teacher-student relationship is weakened (which is often hard for both teacher and student).

\section{LANGUAGE TEACHING AT THE PÔLE UNIVERSITAIRE EUROPÉEN}

The experiment described below was originally initiated by the Pôle Universitaire Européen, which is an organization coordinating activities of the three Strasbourg universities, such as long-term planning and orientation of foreign students. Its Centre de Ressources de Langues (CRL) offers selfstudy courses in English and German to nonspecialist students, meaning those whose main subject is not languages. The CRL supports departments on a contractual basis. At present there are agreements with a dozen departments and CRL offers language tuition to about a thousand students. The CRL is now in its third year of existence, and employs a staff of five full-time teachers (two in German and three in English), plus a part-time head and part-time assistants. Apart from remedial work and general purpose language learning, the CRL focuses on language learning for specific purposes, for use in philosophy, history, economics, biology, etc.

The CRL offers a wide range of learning units based on a number of resources: textbooks, grammars, scientific papers, specialized magazines, novels, short stories, audio cassettes, video cassettes, and educational software. At the moment, CALL is only available in the Economics Department (250 students), and the Biology Department (650 students).

A learning unit is a set of documents referring to one of the learning resources and offering a choice of exercises (and their answers), as well as educational aids such as advice on how to proceed, vocabulary, film scripts, lists of linking words, etc. A unit also refers to one or more methodological 'how to' documents intended to help students with specific aspects of their learning, such as how to summarize a text and how to learn vocabulary. 
Learning units are managed by a database which prints out standardized descriptions, as well as lists of units arranged according to theme, level of difficulty, type of exercise, etc.

The CRL also provides students with the opportunity to have conversation courses with native speakers.

\section{The self-study of English in the Biology Department: general organization}

The CRL and the Biology Department have jointly set up a Language Centre on the department's premises. It caters for 650 licence and maitrise students (third and fourth year students), whose command of English varies greatly. Groups of about 20 students attend a two-hour self-study session every fortnight. The Language Centre also offers open time slots when students may use the Centre's resources freely. The Biology Department has appointed two English teachers who are responsible for the day to day management of the Language Centre. They offer tutoring and guidance to the students, and set the exams. Each self-study session is supervised either by an English teacher or a student employed for that purpose.

The domain specific language learning units are jointly produced by the Department's English teacher and the CRL, under the scientific supervision of a biology professor; the general purpose learning units are mainly provided by the CRL.

\section{Computer assisted language learning}

When the Language Centre was set up in September 1993, CALL was deliberately emphasized as it seemed to be a promising technology which could be put to the test of effectiveness with students.

We used a standard NOVELL network which links 12 PCs; 10 student workstations, 1 teacher workstation, and a server with a 1.2 GB hard disk. The educational software installed consists of a powerful multimedia authoringsystem, other CALL software and CD-ROMs.

\section{Multimedia authoring-system}

The multimedia authoring-system we use is called LAVAC (Laboratoire AudioVisuel Actif Comparatif). It is a Windows-based programme written by a software firm in Montpellier, France [4]. The multimedia lessons, consisting of text, sound and still pictures, are created by the teacher at his station, then stored on the server and used by students at their workstations. During learning sessions students may call for teacher help through the system. The teacher may check work in progress and send written or oral messages to the 
students. At present about fifty self-study units (about half of them general language units, the other half biology and biochemistry units) are available. They use up about $700 \mathrm{MB}$ on the server's disk, which means new arrangements will soon have to be made.

A typical lesson is built around a digitized soundtrack (either a dialogue, a lecture or a specialized article read by a native speaker). The exercises centre on the understanding of the subject (and therefore of the language), the prompting of an oral or written work, or both. Pictures are added for illustrative or explanatory purposes. Up to now we have only been using pictures as ancillary add-ons, but we are currently devising multimedia practical work in biochemistry which depends on soundtrack and exercises organized around a sequence of pictures describing biochemical experiments.

\section{Miscellaneous software}

To complement the multimedia lessons, there are a number of other CALL programmes which offer remedial grammar and language skills, vocabulary acquisition and text comprehension exercises. The word processor facilities are also used to delete, move or copy text easily, and to train students to abbreviate and summarize texts.

\section{CD-ROMs}

CD-ROMs have been installed at two of the workstations with quite a lot of problems. These do not come with standardized working procedures: some of them are Windows-based, some are DOS-based. Some demand cumbersome installation procedures, some none at all. There also is an erratic compatibility between the various CD-ROM drives and sound cards. Added to this nerveracking installation [5] is whimsical operation and problems with such and such part of the machine, be it the video card, the mouse, or whatever resident programme installed. Yet, CD-ROMs are highly popular with the students.

\section{The functioning of the Language Centre}

At the beginning of the year students are instructed in the use of the Language Centre's facilities. They work in a self-study environment with more selfresponsibility, and also more freedom. Attendance is not compulsory. The teacher helps to set objectives based on both the institution's objectives, and the students' own interests and needs. Students set up and carry out their own individual programmes and are encouraged to keep a written record of progress made and difficulties encountered. 
Each session is supervised either by an English teacher or an assisting student. Students in their personal programme can either start work straight away on the computer, go and get an available unit on paper, or ask the supervisor for an audio- or video-cassette, or a CD-ROM.

\section{EVALUATION}

Our Language Centre has been operating for a year and a half now. On the whole, it has worked satisfactorily. However, a number of difficulties has developed which are mostly intrinsic to the self-study situation, but some of which arise from IT.

\section{Problems with self-study}

To check on how self-study would be accepted by students and on the Language Centre organization students were regularly asked to fill out assessment questionnaires and report difficulties.

On the one hand, students seem to be happy to work in freedom, at their own pace, without having to conform to the average pace of a language class. The learning resources are deemed interesting and adequate, and most of them are happy to work in a high tech environment.

On the other hand, some miss the cosiness of a class-room, where students are told what to do, when to do it and how to do it. The main problems are organization of work and assessment of progress. Many students find it difficult to implement their personal learning programme: they work haphazardly and are thus unable to assess progress. Steadily they become more and more unsure of the quality of their work.

Some solutions to these problems are being implemented now. These include better student training in self-study, clearer statement of the institution's expectations, splitting of the curriculum into several independent units which are assessed separately throughout the year (thus helping students to achieve a sense of purpose), regular methodological and remedial tutoring for small groups of students, etc.

\section{Problems with CALL}

After a while a decline in the use of computers was noted. It turned out that students did not always understand what they were supposed to do in multimedia lessons. Also they failed to see how the lessons were related to each other, and therefore were unable to integrate these in their learning programme in a meaningful way. It was not hard to trace those problems to our own lack of experience. 
The main problem was pedagogical. What types of lessons make the best use of the technology? Mere adaptation of existing audio material to multimedia systems is not good enough. There are constraints which act as a filter on the audio material and result in a multimedia lesson with only a subset of its original qualities. Also the visual aspect of multimedia remains unexploited. Also noting that creation of a multimedia lesson requires at least twenty hours of work by a well-trained teacher, it is so much easier to provide the student with a Walkman and a copy of an audio-cassette.

We concentrated on English for specific purposes producing lessons based on specialized articles and lectures in English. This type of lesson is not available on the market and therefore worthwhile to produce ourselves. A happy side-effect was better integration of the Language Centre into the Department of biology and biochemistry. Professors supervised our multimedia lessons increasing their awareness of the Centre.

But we then had to cope with the difficulties of clarity and coherence. As far as clarity is concerned, it took us time and experience to define a standard lesson format and to define a set of rules governing the presentation of lessons in terms of length of sounds, size and place of pictures, types of exercises, availability of help, etc. With respect to coherence the lessons had to be organized into an educationally relevant framework, establishing links between the multimedia lessons and connecting them to the other resources. Multimedia lessons are now integrated into our database helping students to make a better choice of learning materials.

\section{TEACHER TRAINING}

All these difficulties eventually boil down to a single one: teacher training. The concept of self-study has been around for some time, but language centres operating in full scale are still relatively new.

Teaching in a self-study environment requires specific educational qualities. These include clarity (self-study lessons are self-contained units which must be clearly explained), presentation (lessons must come in pleasant, easily recognizable formats), coherence (lessons must be linked into a meaningful framework), team spirit and openness (teachers must accept proof-reading and criticism). Teacher training therefore must include self-study principles, as well as practical training in the educational use of the many media which can be used as learning resources. 


\section{LIBERATING THE LEARNER WITH THE HELP OF IT: A MATTER OF CONTEXT}

CALL, and especially multimedia CALL, can certainly liberate the learner, but only in a suitable context. The mere availability of machines is no guarantee for efficient language learning, except maybe for highly motivated people. At any rate, a clear conception of the computer's educational limitations is necessary. It is futile to try and use IT for educational purposes beyond its scope. No machine can ever be a natural partner in a conversation and give, for example, an intelligent assessment of papers such as essays. It is also a waste of money to use IT where other means are just as, or even more, effective. Why for example go to the trouble of digitizing large chunks of sound or moving pictures when an audio or video cassette can do the same job more costeffectively? CALL should therefore only be one learning resource among others.

\section{CONCLUSION}

Despite some dark periods of despair in which the network broke down, the CD-ROMs refused to work or the students turned away from their computers, this self-study experiment in a high tech environment can on the whole be described as successful. There are no intrinsic failures in the self-study set up or the multimedia tools used. Temporary failures we experienced were caused by extrinsic factors such as inexperience in running a language centre and using IT. We are rather optimistic. For the future we expect Language Centres to share resources on the OSIRIS network linking all Strasbourg University Departments. In the long run, distance language learning may be organized for Internet users.

\section{REFERENCES}

1. Frath, P. (1993) Computer Assisted Teaching and Learning of Languages in French Secondary Schools: Some Changes in Learning, in Informatics and Changes in Learning (eds Johnson, D.C. \& Samways, B.), Elsevier Science Publishers B.V., North Holland, p. 125-132.

2. Dickinson, L. (1987) Self-instruction in Language Learning, CUP.

3. Duda, R. \& Riley, P. (eds) (1991) Learning Styles. PUN, Nancy. 
4. LAVAC (1993) C Puissance 3, Montpellier.

5. Carlton, J. (1994) CD-ROMeurs au bord de la crise de nerfs, in Courrier International, 32. 